\title{
Proposed ICD-11 complex posttraumatic stress disorder, characteristics and symptoms of adults in an inpatient psychiatric setting: A descriptive study
}

\author{
Stadtmann $\mathrm{MP}^{1,3 *}$, Maercker $\mathrm{A}^{2}$, Binder $\mathrm{J}^{\mathrm{3}}$ and Schnepp $\mathrm{W}^{1}$ \\ ${ }^{1}$ University of Witten / Herdecke, Witten, Germany \\ ${ }^{2}$ University of Zurich, Zurich, Switzerland \\ ${ }^{3}$ Integrierte Psychiatrie Winterthur, Winterthur, Switzerland
}

\begin{abstract}
Background: Applying the framework of ICD-11, complex posttraumatic stress disorder will be diagnosed using the core criteria of a posttraumatic stress disorder and the presence of three additional symptoms that identify 'disturbances in self-organization': affective dysregulation, negative self-concept and disturbances in relationships. An understanding of characteristics and the symptom burden of patients with a complex posttraumatic stress disorder, hospitalised in psychiatric hospitals, is vital to develop interventions and therefore improve services.
\end{abstract}

Methods: The recruitment of adults in a psychiatric inpatient setting took place in the form of a consecutive sample. The data base for this prospective descriptive study comprised data collected during regular inpatient treatment available from the internal clinic database: The sociodemographic information was collected using a clinical questionnaire and symptom values were assessed with the Brief Symptom Inventory, the Beck Depression Inventory and the Impact of Events Scale - Revised. Patients were additionally assessed using the International Trauma Questionnaire.

Results: 133 agreed to participate, $47.4 \%(n=63)$ of the patients did not fulfil the inclusion criteria of diagnosis. The final sample comprised 50 female and 20 male participants. On average, the patients were 37.84 years old $(\mathrm{SD}= \pm 11.2)$ and $50.0 \%(\mathrm{n}=35)$, single people. $72.9 \%(\mathrm{n}=51)$ had completed secondary school or had higher education and $84.3 \%(n=59)$ of the participants were unemployed. $92.9 \%$ indicated having a form of childhood traumatic experience and all participants had more than two trauma events. Overall, there were gender differences in the perceived symptom burden and manifestation in the symptom domains.

Conclusion: The findings indicate that there may be several adverse factors related to complex posttraumatic stress disorder. The impairment was much more likely to be severe and have an impact on the functional level. The present research adds new results to the growing literature.

Trial registration: Ethical approval was obtained from the Swiss Cantonal Ethic Commission (BASEC - Nr 201500096). This research was also registered on the World Health Organization WHO Clinical Trials Search Portal, Trial DRKS00012268

\begin{abstract}
Abbreviations: AR: Affect Regulation; AV: Avoidance; BASEC: Business Administration System for Ethics Committees; BDI Beck Depression Inventory; BSI: Brief Symptom Inventory; CPTSD: Complex Posttraumatic Stress Disorder; DGPPN: German Association for Psychiatry, Psychotherapy and Psychosomatics; DESNOS: Disorder Of Extreme Stress, Not Otherwise Specified; DIPS: Diagnostisches Interview bei psychischen Störungen; DRKS: German Clinical Trial Register; DR: Disturbed Relationships; DSO: Disturbances In SelfOrganisation; GSI: Global Severity Index; HRSD: Hamilton Rating Scale For Depression; ICD-11: International Classification of Disease, 11th version; Impact of Event Scale: IES; IES-R: Impact of Event Scale - Revised; ipw: Integrierte Psychiatrie Winterthur; ITQ: International Trauma Questionnaire; MD mass: Missing Data Mass; NSC: negative self-concept; PTSD: Posttraumatic Stress Disorder; RE: Reexperiencing; TH: Sense of Threat; WHO: World Health Organization.
\end{abstract}

\section{Background}

Complex posttraumatic stress disorder (CPTSD) was first described by Herman in 1992 [1]. The author discussed the impact of chronic stress on emotion regulation, self-organisation, self-perception, and interpersonal functioning. Furthermore, she highlighted a possible distinction between posttraumatic stress disorder (PTSD) and CPTSD [1]. Until now, CPTSD has been operationalised for research and clinical practice as a "disorder of extreme stress, not otherwise specified" (DESNOS) [2-4]. In the literature, DESNOS has been characterised by pathological abnormalities in interpersonal relationships, somatisation, affective regulation, dissociation and altered self-schemata [1,4-6]. The beta version of the International Classification of Disease, 11th version (ICD-11), available online since 2015, contains two diagnoses of stress and trauma-related illnesses: posttraumatic stress disorder (PTSD) and complex posttraumatic stress disorder (CPTSD). In 2018, the World Health Organization (WHO) is expected to approve ICD-11 as the latest, official version $[4,7]$.

${ }^{*}$ Correspondence to: Manuel P Stadtmann, MSc, Centre for Trauma Disorders, Integrierte Psychiatrie Winterthur, Technikumstrasse 81, Winterthur, Switzerland, E-mail: manuel.stadtmann@ipw.zh.ch

Key words: complex posttraumatic stress disorder, CPTSD, ICD-11, psychiatry, symptoms, inpatient, mental health, descriptive, ITQ

Received: September 13, 2018; Accepted: September 24, 2018; Published: September 27, 2018 
Recent studies have explored if the newly developed International Trauma Questionnaire (ITQ) can distinguish between classes of patients according to the PTSD and CPTSD symptom profiles as proposed [5,711]. Some discussions are still ongoing as to whether or not the two diagnoses describe different entities $[12,13]$. However, several studies provide sound evidence for the newly proposed diagnosis of CPTSD [5,7-11,14-19]. Since CPTSD is not a sub-diagnosis but rather a sibling disorder, the diagnostics for these two disorders differ. For PTSD, the following three symptom domains are proposed: re-experiencing the traumatic event, avoidance of the event and persistent perceptions of heightened current threat. $[4,5,7,18,20]$. The prerequisite is that the affected person develops the symptoms after a stressful situation of catastrophic extent or exceptional threat. This situation can be, for example, abuse of a physical or mental nature, experience of a natural catastrophe, war experience and accidents. ICD-11 proposes to diagnose CPTSD by using the criteria for PTSD, by the addition of symptoms of the following three domains: affective dysregulation, a negative self-concept and disturbed relationships [4,5,7-10,18,21]. The domain affective dysregulation involves symptoms such as self-harming behaviour, dissociation, emotional numbness, anger outbursts, irritability, excessive crying and anhedonia. This domain also includes being unable to manage one's own emotions and is often referred to as difficulties with emotional regulation. A negative selfconcept comprises low self-esteem, negative beliefs due to traumatic experiences, feelings of guilt and shame. It further involves feelings of worthlessness and no sense of self. Disturbed relationships are based on a lack of skills in building and maintaining close social relationships, a feeling of being cut off from others and not feeling close to another person.

The prevalence of PTSD in the European population is estimated to be between $0.56 \%$ and $6.67 \%$ [22]. In this study, the general prevalence for PTSD in Switzerland was estimated as being in the lower third of the specified range. This calculation considered the different measurement methods, sample sizes, settings and sociodemographic factors of previous research. The results from Burri and Maercker [22] suggest that different aftermaths of war are correlated to the prevalence of PTSD. The literature currently covers few results on the prevalence of CPTSD in clinical samples $[8,12,23]$. In a study on inpatients by Cloitre et al. [5], $36.1 \%$ of the population had CPTSD, 31.8\% had PTSD and $32.1 \%$ had clinically unremarkable symptoms. Furthermore, the research results suggest that, after child abuse, the probability of developing CPTSD is double that of developing PTSD. A study conducted by Wolf et al. [12] estimated a CPTSD prevalence of $13 \%$ for traumatised veterans and a CPTSD prevalence of $0.6 \%$ for the US population.

It has been suggested that CPTSD may be mostly relevant to groups exposed to repeated and prolonged interpersonal trauma and is strongly associated with a more frequent accumulation of distinct types of traumatic experiences and poorer functional impairment $[1,4,8,16,23]$. CPTSD is also understood to be a chronic illness [1,23,24]. Those affected often try to divert or regulate stressful effects by excessive alcohol consumption or self-harming behaviour [24-26]. Closely related to low self-efficacy due to lack of self-regulatory competences, a problem area arises involving inadequate self-care, impairment in quality of life and, indeed, in everyday life itself. These problems can lead, for example, to individuals neglecting to eat and attend to personal care [27]. There is often a strong mistrust, or avoidance of any social contact, due to traumatic experiences and/or any social relationships. Often, patients lack close friends or relatives [28]. In everyday life, dissociative symptoms can lead to severe problems with social interactions. An intense depersonalisation experience, "standing beside oneself", stuporous states or dissociative run-out (fugue) can occur $[29,30]$ during periods of stress. These stressful periods can include things such as being under time pressure or facing a challenging professional situation. These phenomena can lead to social neglect and more intense feelings of shame, guilt and lower self-esteem. Dissociative symptoms may be the result of neurobiological protective systems, which protect the organism from overwhelming burdens $[3,6,29]$.

Symptoms in general are discussed in the literature as a common reason for seeking treatment [31]. During the trajectory of illness, those affected often experience multiple, as well as, competing symptoms $[32,33]$. That condition can alter life quality and everyday life of affected persons [34]. Moreover, not only do these symptoms cause distress, but they can also affect social interactions [35]. A symptom is described as a subjective feature, that is as a subjective individual perception that influences feelings towards the illness [33]. Furthermore, a symptom can be interpreted as a multidimensional and complex phenomenon. More than three symptoms associated with each other are described as a symptom cluster [33,36]. There is currently strong evidence relating to individual symptoms while the study of symptom clusters is described as poor [33]. Therefore, an understanding and description of characteristics and the distinct levels of symptom burden of patients with CPTSD, hospitalised in psychiatric hospitals, is vital for researchers and practitioners to research on CPTSD patients. Consequently, this study focuses on the collection and description of variables, through standardised assessment instruments and characteristics of adult inpatients with CPTSD. These results could serve as a reference, for hypothesis generation and basis for further research.

\section{Aims}

The aims of this study are as follows:

To describe the demographic variables such as gender, age, education, occupational status and marital status for adult CPTSD inpatients.

To identify specific types of trauma exposure and their frequency for adult CPTSD inpatients.

To describe the level of symptom burden for adult CPTSD inpatients through standardised assessment instruments.

\section{Method}

\section{Study design}

This study is the first part of a larger project to investigate the symptom management and the social process of adult inpatients with CPTSD [37]. A single-side prospective descriptive design using routinely collected data was selected to generate the results.

\section{Setting}

The current study was conducted at the institution Integrierte Psychiatrie Winterthur, Zurcher Unterland (ipw). The institution is a large, community-based organisation providing psychiatric services in the city of Winterthur in the Canton of Zurich, Switzerland. The recruitment was carried out in an inpatient mental health ward for psycho-traumatology. The ward treats approximately 200 patients per year and employs 25 clinicians, such as psychiatrists, psychologists, mental health nurses and other therapists. It provides treatment for a diverse adult population from the German speaking region of Switzerland. Inpatient treatment lasts between two and three months. Patients can refer themselves or be referred through a psychiatrist or psychologist. The ward has a capacity for 17 patients. 


\section{Participants and recruitment}

Participants for the current investigation included a sample of adult inpatients whose data was collected through consecutive recruitment from 1.1.2016 until 31.5.2017. All participants received detailed information during their admission phase and the research intention and aims were explained. After the patient agreed to participate in the study informed, written consent was obtained. All patients referred for regular inpatient treatment offered by the ward and who fulfilled the criteria were asked if they wished to participate. The criteria were as follows: it was the patient's first inpatient treatment on the psychotraumatology ward; the patient was between 18 - 60 years old; the diagnosis of CPTSD, based on the ITQ, was fulfilled and the patient had a good knowledge of German. Exclusion criteria included acute or latent suicidality and a main diagnosis other than CPTSD. Patients who might endanger themselves or others were also excluded.

The data base for this quantitative study comprises data that was collected during regular inpatient treatment and was available from the internal clinic database. Timing: $\mathrm{T} 1=$ data were collected during the admission phase by the corresponding practitioner (psychologist or psychiatrist): The socio-demographic information was collected using a clinical questionnaire, and symptom values were assessed with the Brief Symptom Inventory, the Beck Depression Inventory and the Impact of Events Scale - Revised. Patients who agreed to participate in this study were additionally assessed using the ITQ. This procedure was completed within the first week of inpatient treatment.

\section{Instruments}

The International Trauma Questionnaire (ITQ) is the new proposed diagnostic instrument that is currently under development $[5,8,20]$. For this research project, we used the version 1.3 translated from English to German by Knefel, Lueger-Schuster and Maercker in 2015. The scale can be used to generate a self-report ICD-11 PTSD or CPTSD diagnosis $[9,21,38]$. The measure corresponds to the three clusters of PTSD, Reexperiencing (RE) (items P1-P2), Avoidance (AV) (items P3-P4), and Sense of Threat $(\mathrm{TH})$ that is manifested by increased arousal and hypervigilance (items P5-P6). ICD-11 CPTSD is measured by the inclusion of 20 symptoms that describe disturbances in self-organisation (DSO). These items include four clusters, with two clusters relating to affect regulation (AR) characterised by hyper-activation (C1-C5) and deactivation (C6-C9). The third cluster relates to negative self-concept (NSC; C11-C14), the fourth cluster to disturbed relationships (DR; C15-C17). The last three items are relating to impairment (I; C18-C20) $[8,9,38]$.

The response format corresponds to the degree the symptoms bothered the individual in the past month, using a Likert-type ranging from 0 (not at all) to 4 (extremely). The scale can be used to generate a self-report ICD-11 PTSD or CPTSD diagnosis. A diagnosis of PTSD requires a score of $\geq 2$ for at least one symptom in each of its three clusters. A diagnosis of CPTSD requires PTSD diagnosis and the following scores for each of the three DSO clusters. AR for consistency requires a score of $\geq 10$ on items $1-5$ (hyper-activation) or a score of $\geq 8$ on items 6-9 (deactivation). For the NSC items a score of $\geq 8$ and for DR a score of $\geq 6$ are required. In a current study, the reliability estimates were adequate with Cronbach's alpha for the total scale $(\alpha=0.91)$, hyper-activation ( $\alpha=0.73)$, deactivation $(\alpha=0.75)$, negative self-concept $(\alpha=0.83)$, and relational disturbance $(\alpha=0.79)[9,38,39]$.

Three forms of typical psychological reactions in the context of traumatic disturbances have been shown as the consequences of extreme events: intrusion, avoidance and hyperarousal $[40,41]$. The
Impact of Event Scale - Revised (IES-R) measures these three domains [40]. The time required for completion of the IES-R is estimated to be five minutes. The three subscales "intrusion", "avoidance" and "hyperarousal" typically detect forms of individual reactions to, or symptoms of extremely stressful events. There is good psychometric evidence for the German version of this instrument. The internal consistency (Cronbach's alpha) is for the scale intrusions at $\alpha=.90$, for the scale avoidance $\alpha=.79$, for the scale hyperarousal at $\alpha=.90$. The Retest Reliability (three months) for intrusions is $\mathrm{rtt}=.80$, avoidance $\mathrm{rtt}=.66$ and hyperarousal $\mathrm{rtt}=.79$. The intercorrelations between the IES-R and associated "Diagnostisches Interview bei psychischen Störungen” (DIPS) (Diagnostic Interview for Psychiatric Disorders) symptom sums were $r=.53$ (avoidance), $r=.59$ (intrusions) and $r=.72$ (hyperarousal). The responses are recorded at even intervals $(0=$ not at all, $1=$ somewhat, $2=$ moderate, $3=$ fairly, $4=$ extreme), unlike the original IES scale with a five-step response format [40].

Depressive moods are a frequent symptom in traumatic disorders $[4,7,42]$. The Beck Depression Inventory is an assessment instrument often used in clinical practice. It can be used to assess the degree of depression and takes between five and ten minutes to complete [43]. Consisting of 21 items, each item has a score of 0-3. Values from 0 to 9 signify no depression, from 10 to 18 a mild to moderate depression, from 19 to 30 a moderate or severe depression, and 30+ a major depression [43]. Beck's original report showed a correlation coefficient of .86 for the items, and the Spearman Brown correlation for the reliability of the BDI had a coefficient of .93 and a split-half reliability of .86. An alpha coefficient between 0.76 and 0.95 was found in a psychiatric sample [43]. Correlations with the Hamilton Rating Scale for Depression (HRSD) were 0.61 to 0.86 . A correlation of 0.62 with the Hopkins Symptom Checklist was achieved. Checklist depression scores were measured. At the cut-off point of 9 , the sensitivity was $84.6 \%$ and the specificity $86.4 \%[43]$.

The Brief Symptom Inventory (BSI) is the short form of the SCL90. It is a German-language translation by Franke [44]. Its origin can be found in Derogatis's American "Brief Symptom Inventory" (BSI) $[45,46]$. The BSI is an assessment instrument with 53 items for the assessment of subjective impairment by physical and mental symptoms. The time required for completion is between five and ten minutes plus possibly an additional five minutes for instructions. It records the following symptoms: somatisation, compulsiveness, insecurity in social contact, depression, anxiety, aggressiveness/hostility, phobic anxiety, paranoid thinking and psychoticism. Measurement is on a Likert-type (not at all 0, a little 1, moderate 2, strong 3, very strong 4) [44]. For the primary dimensions of the BSI, the reliability values of Cronbach's were between $\alpha=.97$ and .98 (Franke, 1997). The test-retest reliability, measured as a correlation between two measurements before and after one week, yielded satisfactory (anxiety, somatisation, aggression/ hostility, psychoticism) to good (depression, obsessiveness, paranoid thinking, phobic anxiety, social insecurity, Global Severity Index (GSI) reliability values $[44,47]$.

\section{Analyses}

The sociodemographic and medical data of the patients were analysed using the following descriptive statistical methods: Absolute and relative frequencies, mean values, minimum and maximum values, percentage, standard deviations, histograms and bar graphs. The Statistical Package for the Social Sciences 24 (SPSS) software was used for the analyses. Sample size calculation was not required, as all patients were included. The following procedures for dealing with missing values were used: $1111=$ not documented, $2222=$ incomplete or imprecise 
Stadtmann MP (2018) Proposed ICD-11 complex posttraumatic stress disorder, characteristics and symptoms of adults in an inpatient psychiatric setting: A descriptive study

data documented, $3333=$ not collected because of exclusion criteria. If necessary, a MD measurement (Missing Data Measurement) would have been calculated to determine the proportion of missing to existing values. With this procedure, we assumed we could identify concentration tendencies of missing values within the matrix. By applying simple or multiple imputation methods, we attempted to eliminate the issues of partial high information loss in elimination methods.

\section{Results}

\section{Sociodemographic results}

During the sampling period, 138 patients were asked to take part in this research, of which $n=5$ declined and $n=133$ agreed to participate. The response rate in this study was $96.3 \%$. $n=63$ were excluded from the study, having not fulfilled the inclusion criteria of CPTSD diagnosis. After this procedure, the sample consisted of $n=70$. Consequently, we describe in this clinical sample a prevalence for CPTSD of $52.6 \%$. All participants were resident in German speaking parts of Switzerland. $71.4 \%(\mathrm{n}=50)$ of the participants were women and accordingly 28.6 $\%(\mathrm{n}=20)$ were men. Further, $34.3 \%(\mathrm{n}=24)$ of patients were between 30 - 39 years old and $28.6 \%(n=20)$ were between 40 - 49 years old. Patients ranged in age from 18 to 63 years. On average, the patients were 37.84 years old $(S D= \pm 11.2)$. With $50.0 \%(n=35)$, single people were the most frequently represented in the sample, followed by divorced people with $24.3 \%(\mathrm{n}=17)$. At the time of this study, $84.3 \%(\mathrm{n}=59)$ of the participants were either unemployed or unemployable for other reasons (e.g. disability pension or signed off sick). Of all patients, 37.1\% $(n=26)$ lived together with others. The remaining patients were living in different settings and/or alone. Of all patients, $72.9 \%(n=51)$ had a high school diploma or higher education. Table 1 further shows the amount of additional diagnoses in this sample. All patients had at least two diagnoses.

\section{Traumatic events}

In our sample, none of the patients had one single trauma type only. $11.4 \%(\mathrm{n}=8)$ described 2 traumatic events and $18.6 \%(\mathrm{n}=13)$ 3 traumatic events. Patients with 4 traumatic events were with $28.6 \%$ $(n=20)$ most often represented (Table 2, traumatic events frequency). Nearly all patients in this sample described early child abuse in their history, 92.9\% ( $\mathrm{n}=65)$. Followed by the second most commonly reported forms of traumatic event - sexual abuse in adulthood with $77.1 \%(\mathrm{n}=54)$ and neglect as the third most commonly reported exposure with $67.1 \%(\mathrm{n}=47)$ (Table 3-4).

\section{Symptom burden}

Among the ICD-11 CPTSD ITQ items, patients rated item 18 (impairment) with $\mathrm{M}=3.20$ and $\mathrm{SD}= \pm .972$ highest, followed by item 19 with $\mathrm{M}=3.16$ and $\mathrm{SD}= \pm 1.099$. Followed by item 4 (hyper-activation) with $\mathrm{M}=3.13$ and $\mathrm{SD}= \pm 1.076$ similarly to item 13 reflecting one symptom of the negative self-concept cluster with $\mathrm{M}=3.13$ and $\mathrm{SD}=$

Table 1. Sociodemographic variables

\begin{tabular}{|c|c|c|c|c|}
\hline & & $\mathbf{n}$ & $\begin{array}{c}\text { Absolute } \\
\text { percentage (\%) }\end{array}$ & Cumulative percentage (\%) \\
\hline \multirow[t]{2}{*}{ Gender } & male & 20 & $28.6 \%$ & $28.6 \%$ \\
\hline & female & 50 & $71.4 \%$ & $100.0 \%$ \\
\hline \multirow{5}{*}{ Age } & $18-29$ & 15 & $21.4 \%$ & $21.4 \%$ \\
\hline & $30-39$ & 24 & $34.3 \%$ & $55.7 \%$ \\
\hline & $40-49$ & 20 & $28.6 \%$ & $84.3 \%$ \\
\hline & $50-59$ & 9 & $12.9 \%$ & $97.1 \%$ \\
\hline & $60+$ & 2 & $2.9 \%$ & $100.0 \%$ \\
\hline \multirow{4}{*}{ Marital status } & single & 35 & $50.0 \%$ & $50.0 \%$ \\
\hline & married - living together & 12 & $17.1 \%$ & $67.1 \%$ \\
\hline & married - separated & 6 & $8.6 \%$ & $75.7 \%$ \\
\hline & divorced & 17 & $24.3 \%$ & $100.0 \%$ \\
\hline \multirow{4}{*}{ Occupational status } & employed (100\%) & 5 & $7.1 \%$ & $7.1 \%$ \\
\hline & employed (>100\%) & 6 & $8.6 \%$ & $15.7 \%$ \\
\hline & unemployed & 29 & $41.4 \%$ & $57.1 \%$ \\
\hline & unemployable for other reasons & 30 & $42.9 \%$ & $100.0 \%$ \\
\hline \multirow{6}{*}{ Living situation } & living alone & 21 & $30.0 \%$ & $30.0 \%$ \\
\hline & living with others & 26 & $37.1 \%$ & $67.1 \%$ \\
\hline & living alone with nursing support & 10 & $14.3 \%$ & $81.4 \%$ \\
\hline & living in a social institution & 6 & $8.6 \%$ & $90.0 \%$ \\
\hline & $\begin{array}{l}\text { living in a psychiatric unit/ } \\
\text { institution }\end{array}$ & 1 & $1.4 \%$ & $91.4 \%$ \\
\hline & homeless & 6 & $8.6 \%$ & $100.0 \%$ \\
\hline \multirow{6}{*}{ Education } & no education & 5 & $7.1 \%$ & $7.1 \%$ \\
\hline & primary school & 3 & $4.3 \%$ & $11.4 \%$ \\
\hline & apprenticeship & 11 & $15.7 \%$ & $27.1 \%$ \\
\hline & high school & 19 & $27.1 \%$ & $54.3 \%$ \\
\hline & vocational school & 22 & $31.4 \%$ & $85.7 \%$ \\
\hline & university & 10 & $14.3 \%$ & $100.0 \%$ \\
\hline \multirow{5}{*}{ comorbid diagnoses } & 2 diagnoses & 18 & $25.7 \%$ & $25.7 \%$ \\
\hline & 3 diagnoses & 19 & $27.1 \%$ & $52.8 \%$ \\
\hline & 4 diagnoses & 16 & $22.9 \%$ & $75.7 \%$ \\
\hline & 5 diagnoses & 13 & $18.6 \%$ & $94.3 \%$ \\
\hline & 6 diagnoses & 4 & $5.7 \%$ & $100.0 \%$ \\
\hline
\end{tabular}


Stadtmann MP (2018) Proposed ICD-11 complex posttraumatic stress disorder, characteristics and symptoms of adults in an inpatient psychiatric setting: A descriptive study

\pm 1.048 and item 16 reflecting one symptom of disturbed relationships, also with $\mathrm{M}=3.13$ and $\mathrm{SD}= \pm .916$ (Table 5).

In our sample, females had, described on average, in every ICD 11 - DOS cluster, a numeric higher symptom burden than men (Figure 1). An exception was found in the cluster disturbed relationships. In this cluster, in contrast, a greater proportion of males experienced a numeric higher level of symptom burden with $\mathrm{M}=8.95$ and $\mathrm{SD}= \pm$ 1.72 compared to $M=7.82$, in female. (Table 5). Also, in our results with the IES - $\mathrm{R}$, females reported in the domains intrusions with $\mathrm{M}=$ 7.82 and $\mathrm{SD}= \pm 1.97$, Likewise, in hyperarousal with $\mathrm{M}=25.28$ and SD $= \pm 6.95$ numeric higher symptom levels than male, whereas men had

Table 2. Traumatic events frequency

\begin{tabular}{|c|c|c|c|c|}
\hline & & \multirow{2}{*}{$\mathbf{n}$} & \multirow{2}{*}{$\begin{array}{c}\text { Absolute } \\
\text { percentage (\%) }\end{array}$} & \multirow{2}{*}{$\begin{array}{c}\text { Cumulative } \\
\text { percentage }(\%)\end{array}$} \\
\hline & & & & \\
\hline \multirow{7}{*}{ traumatic events } & $\begin{array}{l}2 \text { traumatic } \\
\text { events }\end{array}$ & 8 & 11.4 & 11.4 \\
\hline & $\begin{array}{l}3 \text { traumatic } \\
\text { events }\end{array}$ & 13 & 18.6 & 30 \\
\hline & $\begin{array}{l}4 \text { traumatic } \\
\text { events }\end{array}$ & 20 & 28.6 & 58.6 \\
\hline & $\begin{array}{l}5 \text { traumatic } \\
\text { events }\end{array}$ & 17 & 24.3 & 82.9 \\
\hline & $\begin{array}{l}6 \text { traumatic } \\
\text { events }\end{array}$ & 7 & 10 & 92.9 \\
\hline & $\begin{array}{l}7 \text { traumatic } \\
\text { events }\end{array}$ & 4 & 5.7 & 98.6 \\
\hline & $\begin{array}{l}8 \text { traumatic } \\
\text { events }\end{array}$ & 1 & 1.4 & 100 \\
\hline
\end{tabular}

Table 3. Traumatic events

\begin{tabular}{|c|c|c|}
\hline & Frequencies & Absolute percentage \\
\hline Child abuse & 65 & $92.9 \%$ \\
\hline Sexual abuse in adulthood & 54 & $77.1 \%$ \\
\hline Physical abuse in adulthood & 38 & $54.3 \%$ \\
\hline Domestic abuse & 42 & $60.0 \%$ \\
\hline School violence & 21 & $30.0 \%$ \\
\hline Neglect & 47 & $67.1 \%$ \\
\hline War & 15 & $21.4 \%$ \\
\hline Accident & 16 & $22.9 \%$ \\
\hline
\end{tabular}

Table 4. Descriptive results for CPTSD features (i.e., ITQ items).

\begin{tabular}{|l|c|c|c|c|c|}
\hline & N & Min & Max & Mean & SD \\
\hline CPTSD item 1 (hyper-activation) & 70 & 0 & 4 & 2.90 & 1.374 \\
\hline CPTSD item 2 (hyper-activation) & 70 & 0 & 4 & 3.01 & 1.097 \\
\hline CPTSD item 3 (hyper-activation) & 70 & 0 & 4 & 2.99 & 1.042 \\
\hline CPTSD item 4 (hyper-activation) & 70 & 0 & 4 & 3.13 & 1.076 \\
\hline CPTSD item 5 (hyper-activation) & 70 & 0 & 4 & 2.07 & 1.355 \\
\hline CPTSD item 6 (deactivation) & 70 & 0 & 4 & 3.09 & 1.316 \\
\hline CPTSD item 7 (deactivation) & 70 & 0 & 4 & 2.49 & 1.164 \\
\hline CPTSD item 8 (deactivation) & 70 & 0 & 4 & 2.70 & 1.301 \\
\hline CPTSD item 9 (deactivation) & 70 & 0 & 4 & 2.79 & 1.128 \\
\hline CPTSD item 10 (explorative item) & 70 & 0 & 4 & 2.77 & 1.265 \\
\hline CPTSD item 11 (negative self-concept) & 70 & 1 & 4 & 2.71 & 1.079 \\
\hline CPTSD item 12 (negative self-concept) & 70 & 1 & 4 & 3.00 & 1.063 \\
\hline CPTSD item 13 (negative self-concept) & 70 & 1 & 4 & 3.13 & 1.048 \\
\hline CPTSD item 14 (negative self-concept) & 70 & 0 & 4 & 2.94 & 1.141 \\
\hline CPTSD item 15 (disturbed relationships) & 70 & 0 & 4 & 2.87 & .977 \\
\hline CPTSD item 16 (disturbed relationships) & 70 & 0 & 4 & 3.13 & .916 \\
\hline CPTSD item 17 (disturbed relationships) & 70 & 0 & 4 & 2.81 & 1.054 \\
\hline CPTSD item 18 (impairment) & 70 & 0 & 4 & 3.20 & .972 \\
\hline CPTSD item 19 (impairment) & 70 & 0 & 4 & 3.16 & 1.099 \\
\hline CPTSD item 20 (impairment) & 70 & 0 & 4 & 3.03 & 1.154 \\
\hline
\end{tabular}

Table 5. Comparison of symptom burden assessed with different assessment instruments

\begin{tabular}{|l|l|l|l|l|l|l|l|l|l|}
\hline & \multicolumn{3}{|l|}{ Female } & \multicolumn{3}{l|}{ Male } \\
\hline DSO - hyper-activation & 70 & 5.00 & 20.00 & 14.84 & 3.25 & 5.00 & 19.00 & 12.25 & 5.02 \\
\hline DSO - deactivation & 70 & 4.00 & 16.00 & 11.52 & 3.27 & 3.00 & 15.00 & 9.90 & 3.65 \\
\hline $\begin{array}{l}\text { DSO - negative self- } \\
\text { concept }\end{array}$ & 70 & 8.00 & 16.00 & 12.42 & 2.70 & 8.00 & 16.00 & 10.20 & 2.86 \\
\hline $\begin{array}{l}\text { DSO - disturbed } \\
\text { relationships }\end{array}$ & 70 & 6.00 & 12.00 & 8.46 & 1.97 & 6.00 & 12.00 & 9.70 & 1.72 \\
\hline DSO - impairment & 70 & 4.00 & 12.00 & 9.72 & 2.19 & 4.00 & 12.00 & 8.55 & 2.89 \\
\hline IES - R intrusions & 70 & 7.00 & 35.00 & 25.28 & 7.81 & 8.00 & 35.00 & 24.20 & 6.93 \\
\hline IES - R avoidance & 70 & 5.00 & 40.00 & 23.70 & 8.69 & 6.00 & 36.00 & 26.10 & 7.79 \\
\hline IES - R hyperarousal & 70 & 8.00 & 35.00 & 25.28 & 6.95 & 7.00 & 35.00 & 21.50 & 8.40 \\
\hline BDI Score & 70 & 15.00 & 72.00 & 48.34 & 14.17 & 12.00 & 64.00 & 36.45 & 15.62 \\
\hline BSI - Somatization & 70 & 4.00 & 28.00 & 14.98 & 7.47 & 4.00 & 27.00 & 11.55 & 6.23 \\
\hline $\begin{array}{l}\text { BSI - Obsessive- } \\
\text { Compulsive }\end{array}$ & 70 & 1.00 & 24.00 & 16.56 & 6.07 & 5.00 & 24.00 & 14.30 & 6.21 \\
\hline $\begin{array}{l}\text { BSI - Interpersonal } \\
\text { Sensitivity }\end{array}$ & 70 & 3.00 & 16.00 & 10.22 & 4.09 & 7.00 & 16.00 & 11.00 & 3.11 \\
\hline BSI - Depression & 70 & 4.00 & 24.00 & 13.86 & 5.25 & 2.00 & 24.00 & 9.45 & 5.73 \\
\hline BSI - Anxiety & 70 & 2.00 & 24.00 & 14.64 & 6.56 & 4.00 & 24.00 & 13.00 & 5.46 \\
\hline BSI - Hostility & 70 & 3.00 & 20.00 & 10.52 & 3.58 & 5.00 & 17.00 & 10.40 & 3.52 \\
\hline BSI - Phobic Anxiety & 70 & 2.00 & 20.00 & 10.22 & 6.36 & 2.00 & 19.00 & 8.00 & 5.30 \\
\hline $\begin{array}{l}\text { BSI - Paranoid } \\
\text { Ideation }\end{array}$ & 70 & 1.00 & 20.00 & 9.56 & 5.03 & 3.00 & 20.00 & 7.90 & 4.27 \\
\hline BSI - Psychoticism & 70 & .00 & 20.00 & 10.50 & 5.21 & 4.00 & 20.00 & 8.80 & 3.89 \\
\hline
\end{tabular}

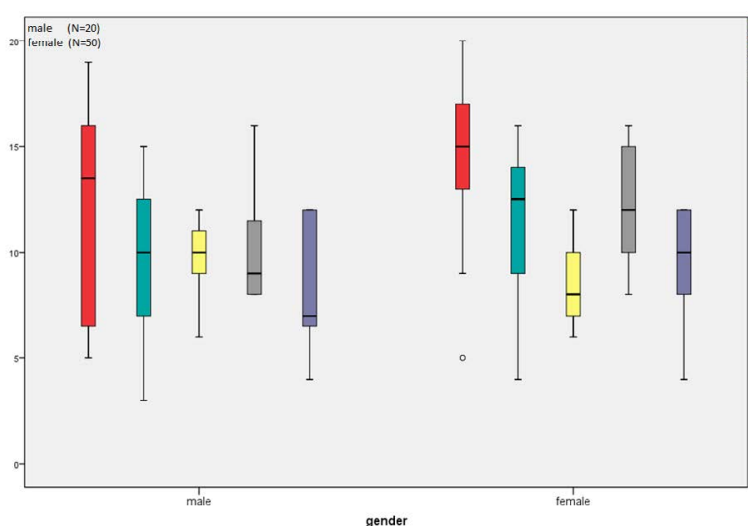

Figure 1. International Trauma Questionnaire: symptom clusters and impairment

with $\mathrm{M}=26.10$ and $\mathrm{SD}= \pm 7.79$ higher numeric results in the domain avoidance (Table 5).

Yet again, in the depressive symptom burden measured by the BDI, women reported numeric higher symptom burden than men with $\mathrm{M}=$ 48.34 and $\mathrm{SD}= \pm 14.17$ compared to $\mathrm{M}=36.45$ and $\mathrm{SD}= \pm 15.62$. as can be seen in Table 5 .

The results for the BSI domains were as follows: For somatisation, males had with $\mathrm{M}=11.55$ with $\mathrm{SD}= \pm 6.23$ a numeric lower score compared to females' $\mathrm{M}=14.98$ and $\mathrm{SD}= \pm 7.47$. Likewise, in the domain obsessive - compulsive, males had with $\mathrm{M}=14.30$ and $\mathrm{SD}= \pm$ 6.21, a numeric lower score compared to females with $M=16.56$ and $\mathrm{SD}= \pm 6.07$. Again, in the domain depression, males had a numeric lower score with $\mathrm{M}=9.45$ and $\mathrm{SD}= \pm 5.73$ than females with $\mathrm{M}=$ $13.86, \mathrm{SD}= \pm 5.25$. Also, for anxiety males had a numeric lower score, $\mathrm{M}=13.00$ with $\mathrm{SD}= \pm 5.46$ compared to females with $\mathrm{M}=14.64$ and $\mathrm{SD}= \pm 6.56$. Additional, phobic anxiety was again rated numeric lower by males with $\mathrm{M}=8.00 \mathrm{M}, \mathrm{SD}= \pm 5.30$ compared to females with $\mathrm{M}$ $=10.22$ and $\mathrm{SD}= \pm 6.36$. Furthermore, males also had numeric lower results in paranoid ideation with $\mathrm{M}=7.90, \mathrm{SD}= \pm 4.27$ compared to $\mathrm{M}$ 
$=9.56$ and $\mathrm{SD}= \pm 5.03$ in females. The last domain where males also had numeric lower results with $\mathrm{M}=8.80, \mathrm{SD}= \pm 3.89$ compared to $\mathrm{M}=10.50$ with $\mathrm{SD}= \pm 5.21$ in females was psychoticism. In contrast to the previous domains, males had a higher numeric score in social insecurity with $\mathrm{M}=11.00, \mathrm{SD}= \pm 4.09$ compared to females with $\mathrm{M}=$ 10.22 and $\mathrm{SD}= \pm 3.11$. Moreover, hostility was the second domain rated numeric higher by males with $\mathrm{M}=12.80, \mathrm{SD}= \pm 3.52$ than females with $\mathrm{M}=10.30$ and $\mathrm{SD}= \pm 3.58$, in addition (Table 5).

\section{Discussion}

The response rate in this study was at $96.3 \%$ extremely high. This element might be due to the circumstances and setting of the data collection. $47.4 \%(n=63)$ patients had to be excluded from our initial sample $(n=133)$, due to not fulfilling the inclusion criteria of CPTSD. In the first study by Cloitre et al. [5], using a latent profile analysis (LPA) to determine whether individuals were distinguishable according to PTSD and CPTSD or not, their results indicated that $36.1 \%$ of their population suffered from CPTSD. Further studies replicated these findings and supported the results $[10,14,17,18]$, whereas other studies found less than $50 \%$ in their sample had a CPTSD diagnosis [19]. Our findings in this sample of $52.6 \%$ of people with CPTSD might be due to the clinical setting of a specialised ward for psycho-traumatology and the result may have been influenced by our sample size. The CPTSDsample comprised 50 female and 20 male participants. The trauma literature has consistently indicated that PTSD is more common among females, with double the prevalence rate of males $[48,49]$. Recent studies also support these assumptions in samples of CPTSD-patients $[19,23]$. Another study suggests, gender appears not to distinguish between PTSD and CPTSD response to trauma experience [23]. Although this is a descriptive study, with a rather small clinical sample, our results are consistent with and support this existent literature.

Under the assumption that CPTSD is associated with less likelihood of having secure attachment [11], our current sociodemographic findings are interesting. $82.9 \%$ of the participants were not married or in a relationship. In addition, $62.9 \%$ were living on their own, or with support from social institutions. This raises the question, if these results may identify the consequences of early forms of interpersonal threat and harm in the form of negative social and socialising outcomes. Despite having a mostly high educational level, at the time of this study $84.3 \%$ of people were unemployed. The result of being unemployed adheres with the findings from Hyland and colleagues [23] that unemployment status significantly increased risk of CPTSD. However, at the same time, this raises the question as to the influencing factors for such a condition. It is possible that CPTSD may be influenced by other adverse social elements described above. We assume, in addition, the high prevalence of comorbidity, ranging from two to six additional diagnoses, may also have an impact on the condition to perform a sufficient function capacity to be able to work. It is common to have comorbid disorders in psychiatric illnesses [50], yet CPTSD was also associated with more comorbidity, severe impairment and other psychiatric conditions [11]. On the one hand, having these comorbid illnesses might have led to different findings. On the other hand, the proposed CPTSD diagnosis, with its symptom clusters, takes this into account and therefore aims to reduce the multiple diagnoses. Our descriptive results relating to additional diagnoses support the occurrence of the proposed CPTSD diagnosis and comorbidity. To extend the work regarding the role of adverse factors (e.g. single status, unemployment, comorbidity) in CPTSD, future research will be important.

In our sample, people indicated having had multiple trauma experiences, ranging in number from two to eight. The literature states that people with multiple types of trauma experience were at an increased risk for the development of CPTSD [11]. Our results support this assumption. Studies have also indicated that childhood and multiple traumatisation are risk factors for CPTSD [5,7,15,51]. There is emerging evidence that childhood traumatic experience is more closely related to CPTSD than to PTSD $[5,15,51]$. Our findings, where $92.9 \%$ of respondents indicated having any form of childhood traumatic experience, are therefore consistent with the existing evidence. However, in this study we defined child abuse as emotional, physical, sexual abuse during childhood. Therefore, we cannot make further differentiated conclusions.

While in some studies the most commonly endorsed symptom domain was affective dysregulation [23], the highest rated items in our sample corresponded to different CPTSD symptom domains (Table 4). Females had, on average, in every ICD 11 - DOS cluster, a higher numeric symptom burden than male. The exception to this finding was in the cluster disturbed relationships, where males experienced a higher numeric level of symptom burden with $\mathrm{M}=8.95$ compared to females with $\mathrm{M}=7.82$. Evidence shows traumas often create some form of impairment such as social withdrawal, disconnection, isolation and avoidance of social interactions [52]. Some of these factors also define the symptom domain disturbed relationships. Results from our measurements with IES-R appear to show supportive indications for those measured with ITQ. Once again, females had a numeric higher symptom burden in intrusions and similarly in hyperarousal. However, in the domain avoidance, males had higher numeric values.

The current literature describes CPTSD patients to be highly impaired by depression, anxiety and sleep disturbances [14]. Our findings support this evidence. Even though females had, yet again, a higher symptom burden compared to males, both fulfilled the BDI "cut-off" for the diagnosis of a severe depression. The measurements also showed moderate depressive ratings with BSI where, once again, females had a higher rating than males. Likewise, in all other domains measured, females had higher numeric values than males with the exception of the domains interpersonal sensitivity and hostility. In these domains males were rated higher than females. These results also agree with our findings from ITQ where men were rated numeric higher in difficulties in social interactions.

These findings may be generated through sample size, form of data collection or other circumstances. However, our results are supported by a recent study with a non-clinical sample where significant gender differences were evident on nearly every symptom cluster [23]. This suggests our results may also highlight some differences in gender, the perceived difficulties in symptoms and response to trauma.

Despite having the strength of providing data directly from clinical practice, there are several limitations we must address. First is the limited comparability. As a study with non-experimental design, there is also no generalisability of the results possible and we cannot make assertions about causality. A further limitation is the data collection in the form of a consecutive sample. Our design did not include a clinical sample other than inpatients in mental health treatment. Although participants in this study were in inpatient treatment for the first time, it is not possible to know the degree to which these symptoms may have been impacted by earlier outpatient therapies. For example, it may be the case that treatment had reduced PTSD symptoms while CPTSD symptoms were more resistant to intervention. A further limitation might be the method of assessing the CPTSD diagnosis. The diagnosis is based on self-report only. It is possible the results will not generalise to other practice settings. Furthermore, the small sample sizes suggest caution against over-interpreting these results and our findings require replication in larger samples. Also, we did not define the trauma event 
child abuse more specific. For instance, divided into, emotional abuse, sexual abuse or physical abuse during childhood. A major limitation is, as a study without a comparison group, we cannot draw inferences about associations, causal or otherwise. Or interpret our results other than with the inclusion and comparison with actual literature. Either did we test any hypothesis. Our results may reflect several bias due to the absence of statistical tests. Moreover, based on the design our results are not repeatable and the study cannot be replicated. However, our results can serve as reference to generate hypotheses for further clinical research. For instance, in rigorous analytical studies with control groups. Finally, as a new scale, it is important to indicate that the ITQ, still requires further validation.

\section{Conclusion}

To our knowledge, this is the first study presenting data of adult inpatients with CPTSD, collected in a specialised ward for psychotraumatology. The results highlight several significant difficulties experienced by adult inpatients with CPTSD. Furthermore, several adverse factors in these patients could be identified (e.g. high unemployment, divorced or unmarried status). This study also documents the prevalence of comorbidity in the form of several additional diagnoses, multiple trauma experiences, types of trauma experience and a high level of symptom burden measured by different validated assessment instruments. Results from other studies further indicate the impairment in people with CPTSD was more likely to be severe and have an impact on the functional level [10]. Thus, targeting these broader symptoms in the context of treatment may aid in promoting greater treatment success. Currently, best-practice treatment approaches for PTSD focus primarily on the reduction of fear-related symptoms [53]. However, literature suggests treatment of CPTSD may require different clinical interventions than the standard evidence-based methods of treating PTSD. Consequently, specific research for instance with control groups are needed. Hence, as already stated, further research and the provision of rigorous research in clinical correlates and characteristics may lead to development of interventions and maximise treatment efficacy for CPTSD [42,54]. The present research adds new results to the growing literature on complex posttraumatic stress disorder.

\section{Declarations}

\section{Authors' contributions}

MS participated in designing the trial and took primary responsibility for interpreting, analysing the data drafting this manuscript. JB participated in managing data collection and in drafting this manuscript. AM, WS participated in designing the study, were involved in interpreting and analysing the data and drafting the manuscript. All authors have read and approved the final manuscript.

\section{Funding}

This study was funded through the institutional budget of the ipw, with no external funding. Additional funding was provided by the German Association for Psychiatry, Psychotherapy and Psychosomatics (DGPPN). DGPPN-Prize for health care professionals in psychiatry, psychotherapy and psychosomatic medicine, 2016.

\section{Ethics approval and consent to participate}

Ethical approval has been obtained from the Cantonal Ethic Commission (BASEC - Nr. 201500096) and the ethic commission of the ipw. This research was registered to the World Health Organization WHO Clinical Trials Search Portal through the German Clinical Trial Register (DRKS), Trial DRKS00012268. Written informed consent for all aspects of the study was obtained from the participants. The patients were always able to withdraw their study participation without explanation. This decision did not affect further inpatient treatment. No new interventions were performed on the patient. Thus, patients were not at increased risk of being harmed through the study.

\section{Consent for publication}

All participants received detailed information, written consent for publication was obtained.

\section{Availability of data and materials}

Data will be available upon request from the first author.

\section{Competing interests}

The authors declare that they have no competing interests.

\section{Authors' information}

Correspondence concerning this article should be addressed to: Manuel P. Stadtmann, Centre for Trauma Disorders, Integrierte Psychiatrie Winterthur, Winterthur, Switzerland Email: manuel. stadtmann@ipw.zh.ch. Research reported in this publication is supported by the Integrierte Psychiatrie Winterthur. The content is solely the responsibility of the authors and does not necessarily represents the official views.

\section{Acknowledgements}

All assessment sheets and data sets are made available by the ipw. The costs incurred from the ethic submission were also paid by ipw. There is no conflict of interest between ipw and the research team. Special thanks to Ms. Lesley-Anne Weiling and Ms. Elaine Melliger for proofreading and editing this paper in terms of the English language.

\section{References}

1. Taylor S, Asmundson GJ, Carleton RN (2006) Simple versus complex PTSD: a cluster analytic investigation. J Anxiety Disord 20: 459-472. [Crossref]

2. McLean LM, Toner B, Jackson J, Desrocher M, Stuckless N (2006) The relationship between childhood sexual abuse, complex post-traumatic stress disorder and alexithymia in two outpatient samples: examination of women treated in community and institutional clinics. J Child Sex Abus 15: 1-17. [Crossref]

3. Van Dijke A, Ford JD, Frank LE, Van der Hart O: (2015) Association of childhood complex trauma and dissociation with complex posttraumatic stress disorder symptoms in adulthood. J Trauma Dissociation, 16: 428-441.

4. Maercker A, Brewin CR, Bryant RA, Cloitre M, Reed GM, et al. (2013) Proposals for mental disorders specifically associated with stress in the International Classification of Diseases-11. The Lancet 381(9878): 1683. [Crossref]

5. Cloitre M, Garvert DW, Brewin CR, Bryant RA, Maercker A (2013) Evidence for proposed ICD-11 PTSD and complex PTSD: a latent profile analysis. Eur $J$ Psychotraumatol 4. [Crossref]

6. Krystal JH, Bennett A, Bremner JD, Southwick SM, Charney DS (1996) Recen developments in the neurobiology of dissociation. In: Handbook of dissociation. edn.: Springer; 1996: 163-190.

7. Maercker A, Brewin CR, Bryant RA, Cloitre M, van Ommeren M, et al. (2013) Diagnosis and classification of disorders specifically associated with stress: proposals for ICD-11. World Psychiatry 12: 198-206. [Crossref]

8. Karatzias T, Shevlin M, Fyvie C, Hyland P, Efthymiadou E, et al. (2017) Evidence of distinct profiles of Posttraumatic Stress Disorder (PTSD) and Complex Posttraumatic Stress Disorder (CPTSD) based on the new ICD-11 Trauma Questionnaire (ICD-TQ). J Affect Disord 207: 181-187. [Crossref] 
Stadtmann MP (2018) Proposed ICD-11 complex posttraumatic stress disorder, characteristics and symptoms of adults in an inpatient psychiatric setting: A descriptive study

9. Hyland P, Shevlin M, Brewin CR, Cloitre M, et al. (2017) Validation of posttraumatic stress disorder (PTSD) and complex PTSD using the International Trauma Questionnaire. Acta Psychiatr Scand 136: 313-322. [Crossref]

10. Perkonigg A, Höfler M, Cloitre M, Wittchen H-U, Trautmann S, Maercker A (2016) Evidence for two different ICD-11 posttraumatic stress disorders in a community sample of adolescents and young adults. Eur Arch Psychiatry Clin Neurosci 266: 317-328.

11. Powers A, Fani N, Carter S, Cross D, Cloitre M, et al. (2017) Differential predictors of DSM-5 PTSD and ICD-11 complex PTSD among African American women. Eur J Psychotraumatol 8: 1338914. [Crossref]

12. Wolf EJ, Miller MW, Kilpatrick D, Resnick HS, Badour CL, et al. (2015) ICD11 Complex PTSD in US National and Veteran Samples: Prevalence and Structural Associations with PTSD. Clin Psychol Sci 3: 215-229. [Crossref]

13. Resick PA, Bovin MJ, Calloway AL, Dick AM, King MW, et al. (2012) A critical evaluation of the complex PTSD literature: Implications for DSM-5. J Trauma Stress 25: 241-251. [Crossref]

14. Elklit A, Hyland P, Shevlin M (2014) Evidence of symptom profiles consistent with posttraumatic stress disorder and complex posttraumatic stress disorder in different trauma samples. Eur J Psychotraumatol 5. [Crossref]

15. Shevlin M, Hyland P, Karatzias T, Fyvie C, et al. (2017) Alternative models of disorders of traumatic stress based on the new ICD-11 proposals. Acta Psychiatr Scand 135: 419-428. [Crossref]

16. Palic S, Zerach G, Shevlin M, Zeligman Z, Elklit A, et al. (2016) Evidence of complex posttraumatic stress disorder (CPTSD) across populations with prolonged trauma of varying interpersonal intensity and ages of exposure. Psychiatry Res 246: 692-699. [Crossref]

17. Cloitre M, Garvert DW, Weiss B, Carlson EB, Bryant RA (2014) Distinguishing PTSD, complex PTSD, and borderline personality disorder: A latent class analysis. Eur $J$ Psychotraumatol. 5: 25097. [Crossref]

18. Knefel M, Garvert DW, Cloitre M, Lueger-Schuster B (2015) Update to an evaluation of ICD-11 PTSD and complex PTSD criteria in a sample of adult survivors of childhood institutional abuse by Knefel \& Lueger-Schuster (2013): A latent profile analysis. European Journal of Psychotraumatology, 6: 25290. [Crossref]

19. Hyland P, Shevlin M, Elklit A, Murphy J, Vallières F, et al. (2017) An assessment of the construct validity of the ICD-11 proposal for complex posttraumatic stress disorder. Psychological Trauma: Theory, Research, Practice, and Policy 9: 1.

20. Krammer S, Simmen-Janevska K, Maercker A (2013) Towards' complex PTSD': German translation of the Trauma Symptom Inventory (TSI) for the assessment of complex trauma Sequelae. Psychother Psychosom Med Psychol 63: 318-326. [Crossref]

21. Hecker T, Maercker A (2015) Komplexe posttraumatische Belastungsstörung nach ICD-11. Psychotherapeut 60: 547-562.

22. Burri A, Maercker A (2014) Differences in prevalence rates of PTSD in various European countries explained by war exposure, other trauma and cultural value orientation. BMC research notes 7: 407. [Crossref]

23. Hyland P, Murphy J, Shevlin M, Vallières F, McElroy E, et al. (2017) Variation in posttraumatic response: the role of trauma type in predicting ICD-11 PTSD and CPTSD symptoms. Soc Psychiatry Psychiatr Epidemiol 2017: 1-10. [Crossref]

24. Huber M: Trauma und die Folgen: Trauma und Traumabehandlung: Junfermann Verlag $\mathrm{GmbH} ; 2012$.

25. Huber M: Trauma und Traumabehandlung. 2. Wege der Traumabehandlung: Junfermann Verlag $\mathrm{GmbH} ; 2003$

26. Reddemann L: Imagination als heilsame Kraft. Zur Behandlung von Traumafolgen mit ressourcenorientierten Verfahren, vol. 141: Klett-Cotta; 2014.

27. Sack M (2004) Diagnostische und klinische Aspekte der komplexen posttraumatischen Belastungsstörung. Der Nervenarzt 75: 451-459.

28. Zoellner LA, Foa EB, Brigidi BD (1999) Interpersonal friction and PTSD in female victims of sexual and nonsexual assault. J Trauma Stress 12: 689-700. [Crossref]

29. Gast U (2004) Der psychodynamische Ansatz zur Behandlung komplexer dissoziativer Störungen. Dissoziative Bewusstseinsstörungen-Theorie, Symptomatik, Therapie Stuttgart: Schattauer 2004: 395-421.

30. Gast U, Rodewald F, Kersting A, Emrich HM (2001) Diagnostik und Therapie Dissoziativer (Identitäts-) Störungen. Psychotherapeut 46: 289-300.

31. Lehavot K, O'Hara R, Washington DL, Yano EM, Simpson TL (2015) Posttraumatic stress disorder symptom severity and socioeconomic factors associated with Veterans Health Administration use among women veterans. Women's health issues 25: 535-541. [Crossref]
32. Dodd M, Janson S, Facione N, Faucett J, Froelicher ES, et al. (2001) Advancing the science of symptom management. J Adv Nurs 33: 668-676. [Crossref]

33. Dodd MJ, Miaskowski C, Lee KA (2004) Occurrence of symptom clusters. J Natl Cancer Inst Monogr: 76-78. [Crossref]

34. Engel CC, Litz B, Magruder KM, Harper E, Gore K, et al. (2015) Delivery of self training and education for stressful situations (DESTRESS-PC): A randomized trial of nurse assisted online self-management for PTSD in primary care. Gen Hosp Psychiatry 37: 323-328. [Crossref]

35. Larson P, Viele C, Coleman S, Dibble S, Cebulski C (1992) Comparison of perceived symptoms of patients undergoing bone marrow transplant and the nurses caring for them. In: Oncology Nursing Forum: 1992: 81-87; discussion 87-88.

36. Smith MJ, Liehr PR: Middle range theory for nursing: Springer Publishing Company; 2013.

37. Stadtmann MP, Maercker A, Binder J, Schnepp W (2017) Symptom management in complex post-traumatic stress disorder (ICD-11), view and experience of patients and their relatives: a mixed methods approach (Research Proposal). BMC Res Notes 10 : 461. [Crossref]

38. Karatzias T, Shevlin M, Fyvie C, Hyland P, Efthymiadou E, et al. (2016) An initial psychometric assessment of an ICD-11 based measure of PTSD and complex PTSD (ICD-TQ): Evidence of construct validity. J Anxiety Disord 44: 73-79. [Crossref]

39. Murphy S, Elklit A, Dokkedahl S, Shevlin M (2016) Testing the validity of the proposed ICD-11 PTSD and complex PTSD criteria using a sample from Northern Uganda. Eur J Psychotraumatol 7: 32678. [Crossref]

40. Maercker A: Impact of Event Scale-revidierte Form (IES-R). Hoyer J, Margraf, eds Angstdiagnostik Berlin, Heidelberg: Springer 2003.

41. Hyland P, Brewin CR, Maercker A (2017) Predictive Validity of ICD-11 PTSD as Measured by the Impact of Event Scale-Revised: A 15-Year Prospective Study of Political Prisoners. J Trauma Stress 30: 125-132. [Crossref]

42. Cloitre M, Courtois CA, Charuvastra A, Carapezza R, Stolbach BC, et al. (2011) Treatment of complex PTSD: results of the ISTSS expert clinician survey on best practices. J Trauma Stress 24: 615-627. [Crossref]

43. Beck AT, Steer RA, Carbin MG (1988) Psychometric properties of the Beck Depression Inventory: Twenty-five years of evaluation. Clinical psychology review 8: 77-100.

44. Franke GH (1997) Erste studien zur güte des brief symptom inventory (BSI). Zeitschrift für medizinische Psychologie, 6: 159-166.

45. Derogatis LR, Savitz KL (1999) The SCL-90-R, Brief Symptom Inventory, and Matching Clinical Rating Scales. 1999.

46. Derogatis LR, Melisaratos N (1983) The Brief Symptom Inventory: an introductory report. Psychol Med 13: 595-605. [Crossref]

47. Franke GH, Reimer J, Hessel A, Philipp T, Heemann U (2002) Lebensqualitätsforschung an chronisch Nierenkranken unter besonderer Berücksichtigung der psychischen Belastung. Zeitschrift für medizinische Psychologie, 11:113-120.

48. Kessler RC, Sonnega A, Bromet E, Hughes M, Nelson CB (1995) Posttraumatic stress disorder in the National Comorbidity Survey. Arch Gen Psych 52: 1048-1060.

49. Christiansen DM, Hansen M (2015) Accounting for sex differences in PTSD: A multivariable mediation model. Eur J Psychotraumatol 6: 26068. [Crossref]

50. Kagabo R, Kleinschmit K, Clark C, Hashibe M, Kim J (2016) A Descriptive Study of Pediatric Inpatients at an Academic Psychiatric Hospital. Psychiatry Ment Health 1(2).

51. Nickerson A, Cloitre M, Bryant RA, Schnyder U, Morina N, et al. (2016) The factor structure of complex posttraumatic stress disorder in traumatized refugees. Eur $J$ Psychotraumatol 7: 33253. [Crossref]

52. Johnson DM, Sheahan TC, Chard KM (2004) Personality disorders, coping strategies, and posttraumatic stress disorder in women with histories of childhood sexual abuse. $J$ Child Sex Abus 12: 19-39. [Crossref]

53. Foa EB, Keane TM, Friedman MJ, Cohen JA (2008) Effective treatments for PTSD practice guidelines from the International Society for Traumatic Stress Studies: Guilford Press; 2008.

54. Ford JD (2015) Complex PTSD: research directions for nosology/assessment, treatment, and public health. Eur J Psychotraumatol 6: 27584. [Crossref]

Copyright: (C2018 Stadtmann MP. This is an open-access article distributed under the terms of the Creative Commons Attribution License, which permits unrestricted use, distribution, and reproduction in any medium, provided the original author and source are credited. 